\title{
Reflexos e reflexões sobre Educação Matemática e inclusão a partir de uma aula para surdos, e um surdocego
}

Reflexes and reflections on mathematics education and inclusion from a class for the deaf and one deaf-blind

\author{
Edson Pinheiro Wanzeler ${ }^{1}$ \\ Elielson Ribeiro de Sales ${ }^{2}$
}

\section{Resumo}

O presente texto, de abordagem qualitativa, construído a partir de revisão de literatura e resgate de registros audiovisuais da pesquisa de um professor de matemática em uma unidade especializada na educação de surdos no município de Belém/PA, no ano de 2008, tem por objetivo refletir acerca da importância do re/conhecer a individualidade do sujeito e a necessidade de encontrar uma forma de comunicação que permita uma interação para o processo socioeducacional, a partir de um episódio em aulas de matemáticas com alunos surdos e uma aluna surdocega. Para isso, o texto está constituído em três episódios que apresentam reflexões sobre a educação matemática e inclusão de alunos exclusos dentre um grupo de minoria, em geral, excluídos pela própria sociedade, com o exemplo de Ana, uma aluna surdocega, estudante de uma turma de alunos surdos. Os resultados das reflexões indicam que precisa se conhecer e construir uma comunicação e iteração para que a inclusão ocorra em qualquer ambiente social e educacional, em especial em aulas de matemática.

Palavras-chave: educação Matemática; educação inclusiva; surdos; surdocego.

\section{Abstract}

This paper, made in qualitative approach built from literature review and the audiovisual records retrieval from the research of a mathematics teacher in a unit specialized on deaf education in the city of Belem/PA, in 2008, aims to reflect on the recognition and acknowledgment importance of individuality and the need to find a new form of communication that allows an interaction for the socio-educational process from a situation in mathematics class involving deaf students and one deaf-blind student. The text consists on three parts that present reflections on mathematics education and the inclusion of excluded students from a minority group generally excluded by society itself, with the example of Ana, a deaf-blind student, in a deaf student class. The results on the reflections show that it is necessary to know about communication and to build an interaction, in order for the inclusion to happen in any social and educational environment, especially in mathematics classes.

Keywords: mathematics education and inclusion; inclusive education; deaf people; deafblind

\footnotetext{
${ }^{1}$ Universidade Federal do Amazonas | wanzelerjr@gmail.com

2 Universidade Federal do Pará | esales@ufpa.br
} 


\section{Introdução}

Discutir relações, percepções e processos inerentes à Educação Matemática e à inclusão de alunos público-alvo da educação especial, hoje, para nós, configura-se como uma nova forma da sociedade visualizar a possibilidade de ensinar matemática com qualidade para todos os alunos presentes no contexto escolar, independentes de características ou dificuldades que o sujeito possa apresentar, de maneira singela ou acentuada, ao serem comparados com os demais.

Neste sentido, compreender a importância do reconhecer as diferenças e a buscas por uma interlocução entre os envolvidos no contexto socioeducacional apresenta-se hoje, para nós, como alguns dos principais pontos em relação à inclusão de qualquer pessoa, exclusa socialmente por qualquer peculiaridade.

Deste modo, o presente texto tem por objetivo refletir acerca da importância do re/conhecer a individualidade do sujeito e a necessidade de encontrar uma forma de comunicação que permita uma interação para o processo socioeducacional, em aulas de matemática.

Para isso, a pesquisa de abordagem qualitativa foi idealizada a partir de discussões no Grupo de Pesquisa Ruaké e elaborada a partir de revisão de literatura em autores, como, por exemplo, Skliar (2006), D'Ambrosio (1986), Smith e Ryndak (1999), e resgate de registros audiovisuais da pesquisa de um professor de matemática em uma unidade especializada na educação de surdos no município de Belém/PA, no ano de 2008.

Deste modo, o texto está divido em dois episódios (um narrativo e um reflexivo), os quais refletem a importância do reconhecimento da individualidade e peculiaridade da comunicação entre os sujeitos para o processo de ensino e aprendizagem e, como a Educação Matemática e inclusão deve reconhecer o aluno como um indivíduo único. Por fim, apresentamos nossas considerações a respeito do estudo.

\section{Episódio 1- A educação, a surdez e a surdocegueira - breves conceitos}

Compreendendo que "a educação abrange os processos formativos que se desenvolvem na vida familiar, na convivência humana, no trabalho, nas instituições de ensino e pesquisa, nos movimentos sociais e organizações da sociedade civil e nas manifestações culturais" (BRASIL, LDB 9.394, de 1996, art. 1), falar em educação de pessoas surdas, hoje em dia, tem sido dialogar com a atual proposta educacional para este público; a educação bilíngue, a qual deve ser realizada em escolas ou classes de educação bilíngue, nas quais "[...] a Libras e a modalidade escrita da Língua Portuguesa sejam línguas de instrução utilizadas no desenvolvimento de todo o processo educativo". (BRASIL, Decreto 5.626, de 2005, Art. 22, § $\left.1^{\circ}\right)$

\footnotetext{
3 Palavra do vocabulário Tupi que significa "perto, ao lado, junto". O Ruaké é um Grupo de Pesquisa em Educação em Ciências, Matemáticas e Inclusão do Instituto de Educação Matemática e Científica (IEMCI) da Universidade Federal do Pará (UFPA).

4 "[...] considera-se pessoa surda aquela que, por ter perda auditiva, compreende e interage com o mundo por meio de experiências visuais, manifestando sua cultura principalmente pelo uso da Língua Brasileira de Sinais Libras." (BRASIL, Decreto5.626, de 2005, art. 2)
} 
E em geral, neste contexto, de escolas, classes e educação bilingue, que, no município de Belém-PA, encontramos alunos surdos compartilhando os espaços educacionais com alunos com surdocegueira, "[...] uma deficiência singular que apresenta perdas auditivas e visuais concomitantemente em diferentes graus, levando a pessoa com surdocegueira a desenvolver diferentes formas de comunicação para entender e interagir com a sociedade". (IBC, 2018, online)

Essa convivência, entre surdos, surdos associados ${ }^{5}$ e surdocegos, é capaz de nos presentear com diferentes realidades, experiências, emoções e sensações, haja vista a multiplicidade de singularidades que podem coexistir em um mesmo ambiente. Pois, mesmo compartilhando de características em comum, neste caso a surdez, cada sujeito é único, e possui suas necessidades e potencialidades. Todavia, de acordo com Almeida (2015, p. 166)

A surdocegueira tem se apresentado como um tema ainda pouco explorado na literatura especializada brasileira, quando comparada à produção teórico-científica sobre outras deficiências. Durante muito tempo, a perda sensorial da visão e audição, concomitantemente, caracterizou-se a partir dos aspectos da múltipla deficiência, e não a partir da compreensão de uma deficiência específica, com características e especificidades muito próprias.

Nessa perspectiva, que apresentamos a seguir algumas memórias de uma pesquisa sobre educação matemática e educação de surdos, que tinha no corpo de pesquisados alunos surdos de uma instituição especializada, na qual frequentava uma aluna com surdocegueira, que gerou estranhamento e inquietação em todos os envolvidos durante a produção dos dados da pesquisa, e que hoje, contribui para uma possível forma de perceber o ensino de matemática em uma perspectiva inclusiva.

\section{Episódio 2 - Revisitando memórias - Ana: uma "excluída" entre os "excluídos"}

Ao revisitarmos o passado de um professor-pesquisador, encontramos, em uma de suas pesquisas desenvolvidas em torno do ensino de matemática para alunos surdos, um episódio marcante com cinco estudantes de uma escola especializada na educação de surdos em Belém-PA, dos quais existia Ana ; uma aluna surdocega.

Ana era uma menina, com 13 anos e cinco meses de idade no início da pesquisa, no ano de 2008, e apresentava surdez congênita neurossensorial profunda bilateral e baixa visão. Segundo relatos de sua mãe, durante a pesquisa, Ana estava perdendo gradativamente a visão e frequentava a instituição desde os 10 anos de idade. Não emitia sons e não fazia uso da oralidade, nem mesmo com interlocutores ouvintes, comunicando-se somente por meio de sinais.

Neste contexto, para o pesquisador, era perceptível que os pares escolares de Ana, por serem surdos, já eram os excluídos de salas de aula dos "não deficientes". E, naquele momento, no ambiente dos surdos, não havia espaço para uma surdocega. Entretanto,

\footnotetext{
${ }^{5}$ Consideramos neste estudo, surdos associados, as pessoas com perda auditiva, que se compreende como surdo, de acordo com a legislação, e que apresentam uma segunda deficiência, seja ela de caráter físico ou intelectual.

6 Nome fictício adotado para preservar a identidade do participante da pesquisa.
} 
salientamos que essa exclusão não se dava somente pelos pares de Ana, pois ao analisar o material audiovisual, o pesquisador percebeu que ela sequer aparecia na maioria das filmagens, e quando aparecia, estava deslocada do grupo que interagia, embora muitas vezes parecesse querer participar efetivamente das atividades desenvolvidas pelo pesquisador.

Nesse sentido, temos a primeira reflexão a respeito da inclusão, apresentada na fala de Lima (2004, p. 197, grifo nosso) ao afirmar que "A inclusão, como discutida na Declaração de Salamanca, defende a inserção do aluno dito com necessidades especiais no contexto da sala de aula. Valoriza o diferente, a heterogeneidade e a dessemelhança. Contudo, não leva em conta que há diferença na diferença".

Nesta senda, ao olharmos para a educação de surdos, temos que os processos de inclusão se referem, na maioria dos casos, única e exclusivamente, à experiência de alunos surdos dividindo a mesma sala de aula com alunos ouvintes. No caso de Ana, tínhamos uma experiência diferente do habitual; tínhamos uma aluna surdocega tentando ser incluída no grupo dos surdos.

Sobre essa ótica, percebemos que abordar a questão da inclusão/exclusão não significa vê-la como algo vivido, apenas por comunidades culturalmente diferentes ou, no caso, por grupos rotulados como "deficientes". Atualmente, o problema da inclusão/exclusão vem afetando a todos nas suas mais variadas formas, ou seja, todos podem ser excluídos de alguma situação e incluídos em outra. Não existe alguém completamente incluído ou completamente excluído (PINTO, 2000), no caso de Ana o grupo a excluía por não conseguir estabelecer um canal de comunicação efetivo com ela, isso gerava um processo de exclusão de forma inconsciente.

Entendemos assim, que uma das principais vias para a inclusão chama-se: Comunicação, mas em um sentido em que a linguagem oral e a escrita não são as principais formas que utilizamos para estabelecer comunicação uns com os outros. Pois, quando falamos de alunos com deficiência, essas formas de comunicação podem configurar-se em um obstáculo, principalmente se nos apoiarmos apenas nessas vias tradicionais de comunicação, e sim a objetividade da interação entre os sujeitos por qualquer mecanismo que permita essa experiência.

Neste sentido, Smith e Ryndak (1999, p. 110) nos dizem que

[...] a mera proximidade não garante interações sociais de alto nível, necessitando de interações cuidadosamente planejadas. É fundamental ao desenvolvimento nos domínios acadêmico e social a capacidade do aluno de se comunicar e interagir com os colegas e com os adultos. A comunicação é a chave para o sucesso em ambas as áreas. Sendo assim, a comunicação surge, nos ambientes escolares, como meio de interação fundamental no qual todos os alunos, "deficientes e normais", podem indicar aos professores se os objetivos curriculares são ou não alcançados.

Em termos metodológicos, é de fundamental importância que o professor desenvolva possibilidades de uso diferenciado dos artefatos pedagógicos, de maneira a possibilitar a abertura de canais de comunicação entre ele e os alunos e entre os próprios alunos (SMITH; RYNDAK, 1999).

Não faz muito tempo que as deficiências desses alunos seriam boas razões para que fossem mantidos apenas no convívio familiar, vivenciando situações de aprendizagens aleatórias e não formais voltadas para as suas necessidades básicas. Entretanto essa situação vem mudando a cada dia, à medida que mais familiares e profissionais tomam consciência 
do processo educativo da pessoa com deficiência e da importância da comunicação e interação nos diferentes ambientes sociais aos quais somos expostos.

Sobre as atividade desenvolvidas na pesquisa, temos que foram trabalhados 17 (dezessete) problemas aditivos elaborados pelo professor-pesquisador, formado em licenciatura em matemática, a época mestrando de um programa de pós-graduação em educação em ciências e matemática de uma universidade pública, sendo todo o processo de construção e de execução, sob a coordenação do professor orientador da pesquisa.

Para a realização da pesquisa, cujo objetivo era investigar se o quadro de escrever seria um artefato pedagógico importante para a comunicação entre o professor e os alunos surdos, dado que sua principal via de comunicação é o canal visual, as interações se deram em sala de aula por meio da língua de sinais nas aulas de matemática em atividades de resolução de problemas aditivos.

Em geral, a rotina de sala de aula foi:

- As atividades eram iniciadas com a interpretação do problema e esclarecimento das dúvidas, dos alunos acerca do problema aditivo, por meio da Língua Brasileira de Sinais (Libras);

- Em seguida, cada aluno resolvia de forma individual em sua prancheta o problema e posteriormente cada aluno mostrava a sua resolução para os demais colegas.

Com o desenrolar das atividades o pesquisador começou a observar que Ana não se integrava no grupo, qualquer que fosse a atividade. Não conseguia dar nenhuma resposta satisfatória, quando era chamada ao quadro para resolver os problemas aditivos. Associado a isso, percebemos também que somente o quadro também não ajudava no processo de interação social do grupo na sua totalidade. O que levou o pesquisador a apresentar os problemas no retroprojetor associado ao quadro para então discuti-los com os alunos.

Em um dos encontros, no momento em que Ana foi ao quadro, ela iniciou o diálogo com a professora e, após alguns minutos de negociação de significados ${ }^{7}$ entre as duas, eis que ela deu a primeira resposta significativa para a professora que, em Libras, deu a entenderIhe que havia acertado a solução.

Ao receber essa informação, Ana explodiu de alegria e saiu por toda a sala pulando e comemorando com todos os presentes, inclusive da equipe de pesquisadores.

Nesse contexto e considerando que a matemática possui uma linguagem especial com simbologia própria para domínio de seus conceitos, fazem-se necessários estudos que produzam processos adaptativos de comunicação entre os atores do processo ensino e aprendizagem desta ciência que, longe de promover inclusão, é comumente usada para se promover a exclusão social mesmo daqueles alunos ditos normais. Danyluk (2002) revela que os alunos são treinados, condicionados e instruídos, em práticas que reforçam o distanciamento da leitura da linguagem matemática. E a autora enfatiza que "[...] não se lê apenas a linguagem mostrada pelo discurso expresso por palavras. É possível ler os sinais

\footnotetext{
7 Bishop e Goffree (apud PONTE et al., 1997, p. 88) nos afirmam que essa construção de significados evolui por aproximações sucessivas. Segundo os autores, só é possível partilhar significados a partir do momento em que estes se tornam públicos ou visíveis. Nesta perspectiva, a aprendizagem assume um caráter coletivo. E sublinham a possibilidade da negociação de significados diminuir com o aumento do controle exercido pelo professor sobre a dinâmica da aula. Esses autores afirmam que é impossível haver negociação de significado entre duas partes se uma delas domina ou tem controle sobre a outra e que, "para falar sobre negociação, as duas partes devem se aceitar como iguais ou, no mínimo, elas têm de respeitar, mutuamente, suas perspectivas".
} 
emitidos pela natureza, assim como a tela de um pintor, os gestos corporais, os olhares das pessoas" (DANYLUK, 2002, p. 18, grifo nosso).

Portanto, comunicar suscita a possibilidade de haver interação entre pessoas com o objetivo de compartilhar algo. Porém, a comunicação positiva, no sentido de resultar de fato num ganho real para todos daquilo que está sendo compartilhado, é seguramente o diálogo que se configura como "a troca ou discussão de ideias, de opiniões, de conceitos, com vista à solução de problemas, ao entendimento ou à harmonia" (FERREIRA, 2004). Essa definição de diálogo, portanto, pede a negociação de significados entre os atores do processo comunicativo, o que nos remete, no caso da Educação Matemática, para um processo de discussões matemáticas, que podemos comparar com um drama protagonizado por professor e alunos envolvidos em alguma atividade matemática, cada um com seu papel, porém engajados em uma mesma atividade indivisível.

Professor e alunos não falam por si sós, mas trazem, em suas falas, as suas experiências em outros contextos socioculturais. As vozes dos diferentes atores se encontrariam, de forma harmoniosa, na atividade matemática, exigindo a negociação de significados.

Objetos, eventos e conhecimentos em sala de aula são concebidos de formas diferentes pelas pessoas envolvidas e, como consequência, constroem, individualmente, diferentes significados matemáticos. Um significado considerado-como-compartilhado pode ser construído por meio da negociação de significados entre professores e alunos (ALRO; SKOVSMOSE, 2006).

Havendo, então, a aceitação e o respeito mútuo das diferentes perspectivas, é possível que haja uma negociação de significados entre professor e alunos e, por meio do diálogo, que cada um possa avaliar sua compreensão das falas dos outros.

É a partir desta experiência com a Ana, que apresentamos uma reflexão sobre a educação matemática e inclusão, para todos, professores e alunos, com ou sem deficiência.

\section{Episódio 3 - Reflexões sobre Educação Matemática e Inclusão}

Que tal se começássemos essa reflexão ensaio ensinando/aprendendo a seguinte definição:

(1) Mãos abertas, palmas para baixo, Mãos cruzadas pelos dedos. Balançar os dedos das mãos. / (2) Mão vertical aberta, palma para trás, dedos separados tocando o queixo. Balançar os dedos / (3) Mão em M balançando para cima e para baixo. / (4) Mão em M balançando para direita e para esquerdå: É a ciência das relações entres os números, quantidades, grandezas e operações. Estão incluídas a Aritmética, a Álgebra, Trigonometria e Geometria9 .

Poderíamos então continuá-lo sem a preocupação se você entendeu ou não do que se trata essa definição, sem nos importarmos se o ensino e aprendizagem do conceito foram realizados de forma aceitável, enfim, apenas continuarmos o texto. Todavia, estaríamos mecanicamente reproduzindo ações, discursos, metodologias etc., que tanto subjugamos, mas que infelizmente em determinados momentos, em um ato falho, realizamos.

\footnotetext{
8 (CAPOVILLA; RAPHAEL; MAURICIO, 2012, p. 1662-1663)

9 (SOARES, 2005, p. 121)
} 
Sendo assim, que tal reescrevermos a definição da seguinte maneira: "Matemática: É a ciência das relações entres os números, quantidades, grandezas e operações. Estão incluídas a Aritmética, a Álgebra, Trigonometria e Geometria" (SOARES, 2005, p. 121).

Talvez agora, o conhecimento tenha sido processado por você de forma mais clara, haja vista que utilizamos elementos totalmente pertencentes a sua realidade, na qual respeitamos sua limitação como leitor/a, neste momento, que assim como nós, tem o direito de viver experiências diferentes e construir seu próprio conhecimento. Pois, segundo D'Ambrosio (2008, p. 18),

Todo conhecimento é resultado de um longo processo cumulativo de geração, de organização intelectual, de organização social e difusão, naturalmente não dicotômicos entre si. Esses estágios são normalmente de estudos nas chamadas teoria da cognição, epistemologia, história e sociologia, e educação e política. O processo como um todo, extremamente dinâmico e jamais finalizado, está obviamente sujeito a condições muito especificas de estímulo e de subordinação ao contexto natural, cultural e social. Assim é um ciclo de aquisição individual e social de conhecimento.

Deste modo, partindo dessa premissa do conhecimento, a busca por respeitar a individualidade de cada aprendiz se faz presente de maneira mais corriqueira nos discursos de pesquisadores e profissionais que ensinam matemática. $O$ que nos leva a perceber a importância do conhecer o aluno para além do indivíduo em sala de aula.

Neste sentido, em meio a uma "guerra" de nomenclaturas existente nos campos das pesquisas em Educação Especial, Educação Inclusiva e Educação Matemática nos percebemos no atual contexto educacional intrigados com a tríade Educação, Matemática e Inclusão, que entendemos hoje como uma nova forma de visualizar o ensino de matemática para todos.

Desta forma, concordamos com o pensamento de Skliar (2006), ao elucidar que

Estamos assistindo nas últimas décadas - mas também produzindo e fabricando - a um turbilhão irrefreável de mudanças educacionais: mudanças nos parâmetros curriculares nacionais, mudanças nas leis de acessibilidade, mudanças na universalização do acesso à escola, mudanças na obrigatoriedade do ensino, mudanças na passagem entre o tipo de escola quase sempre excludente e (em aparência) a fundação de outro tipo de escola que se pretende inclusiva, que se pretende para todos etc. (SKLIAR, 2006, p. 16, grifo nosso)

Nesta senda, conhecer os elementos que compõe essa nova forma de visualizar uma educação para todos, neste momento em especial o que tangencia o ensino da Matemática se faz fundamental na atuação do professor/educador, que, de acordo com Fiorentini e Lorenzato (2007, p. 4-5, grifo do autor),

[...] tende a conceber a matemática como um meio ou instrumento importante à formação intelectual e social de crianças, jovens e adultos e também do professor de matemática do ensino fundamental e médio e, por isso, tenta promover uma educação pela matemática. Ou seja, o educador matemático, na relação entre educação e matemática, tende a colocar a matemática a serviço da educação, priorizando, portanto, esta última, mas sem estabelecer uma dicotomia entre elas. 
Neste direcionamento, vislumbrar diferentes métodos e metodologias que possam levar ao êxito de uma educação de qualidade mostra-se como uma das principais metas de educadores e pesquisadores em Educação Matemática, considerando a constante busca pela melhoria do ensino desta disciplina. Pois, nos apropriando das palavras de D'Ambrosio (2008, p. 7-8, grifo do autor):

[...] [Vemos] a disciplina matemática como uma estratégia desenvolvida pela espécie humana ao longo de sua história para explicar, para entender, para manejar e conviver com a realidade sensível, perceptível, e com o seu imaginário, naturalmente dentro de um contexto natural e cultural. [...] Trata-se da construção de corpos de conhecimento em total simbiose dentre de um mesmo contexto temporal, que obviamente tem variado de acordo com a geografia e a história dos vários grupos culturais a que eles pertencem - famílias, tribos, sociedades, civilizações. A finalidade maior desses corpos de conhecimento tem sido a vontade, que é efetivamente uma necessidade, desses grupos culturais de sobreviver no seu ambiente e de transcender, espacial e temporalmente, esse ambiente.

O que nos leva a perceber a importância de um aprendizado de qualidade dos conteúdos da disciplina, em um cenário, de constantes mudanças, que para nós, imbrica-se em uma cultura de diversidades, possibilidades e escolhas no atual contexto social. Tomando essa diversidade por premissa no processo do ensino e aprendizagem "[...] nos conduz a atribuir à Matemática o caráter de uma atividade inerente ao seu humano, praticada com plena espontaneidade, resultando de seu ambiente sociocultural e consequentemente determinada para realidade material na qual o indivíduo está inserido" (D'AMBROSIO, 1986, p. 36).

Deste modo, passamos a inferir que esta ciência está para além dos cálculos produzidos nos cadernos durante as aulas, e sim na formação do constructo social que realiza de forma consciente e inconsciente o conhecimento matemático gerado de suas ações do cotidiano.

Neste sentido, começamos então a perceber a necessidade de buscar mecanismos para que esse processo de abstração seja natural e que atinja o aluno de forma que ele não tenha uma percepção equivocada da matemática, como algo difícil, e sim como um elemento de transição de formas de conhecimentos. Para isso, trazemos a essa discussão a Educação Matemática,

[...] uma área de conhecimento das ciências sociais ou humanas, que estuda o ensino e aprendizagem da matemática [e] [...] caracteriza-se como uma práxis que envolve o domínio do conteúdo específico (a matemática) e o domínio de idéias e processos pedagógicos relativos à transmissão/assimilação e/ou à apropriação/construção do saber matemático escolar. [A qual é] [...] resultante das múltiplas relações que se estabelecem entre o específico e o pedagógico num contexto construído de dimensões histórico-epistemológicas, psicocognitivas, histórico-culturais e sociopolíticas (FIORENTINI, 1989, p. 1 apud FIORENTINI; LORENZATO, 2007, p. 5, grifos do autor).

Então nesta perspectiva de construção do sujeito e consequentemente aceitação das diferenças, começamos a perceber a existência do pensamento inclusivo na Educação Matemática, por encontramos princípios básicos instituídos pela proposta de Educação 
Especial na perspectiva da Educação inclusiva, que corroboram entre si quando discursam o reconhecimento das particularidades dos alunos. Pois,

O movimento mundial pela educação inclusiva é uma ação política, cultural, social e pedagógica, desencadeada em defesa do direito de todos os alunos de estarem juntos, aprendendo e participando, sem nenhum tipo de discriminação. A educação inclusiva constitui um paradigma educacional fundamentado na concepção de direitos humanos, que conjuga igualdade e diferença como valores indissociáveis, e que avança em relação à idéia de eqüidade formal ao contextualizar as circunstâncias históricas da produção da exclusão dentro e fora da escola (BRASIL, 2008, p. 1, grifos nossos).

E ao adentrarmos nessa discussão sobre Inclusão e Educação Matemática, percebemos a necessidade de esclarecer algumas características que entendemos como cruciais ao bom desenvolvimento de práticas educacionais em uma perspectiva inclusiva. Para isso, adotamos o posicionamento de Rodrigues (2006, p. 11, grifo do autor), ao nos afirmar que: "Quando se fala inclusão, é importante distinguir duas dimensões que talvez tenham tempos de implementação metodológicos de atuações distintas: uma que chamaríamos de inclusão essencial e outra inclusão eletiva".

Essa separação dimensional da inclusão se faz necessárias devido a constante separação dos alunos que "podem" aprender matemática e os que "nunca aprenderão" este conteúdo, muito comum nos discursos docentes. Deste modo, temos que:

A inclusão essencial é a dimensão que assegura a todos os cidadãos de dada sociedade o acesso e a participação sem discriminação a todos os seus níveis de serviço. Assim a inclusão essencial pressupõe que ninguém pode ser descriminado por causa de uma condição pessoal no acesso à educação, a saúde, emprego, lazer, cultura etc. É uma questão que se prende com os direitos humanos e com uma acepção básica de justiça social. [...] [Já a dimensão eletiva da inclusão] assegura que, independentemente de qualquer condição, a pessoa tem o direito de se relacionar e interagir com os grupos sociais que bem entender em função dos seus interesses. (RODRIGUES, 2006, p. 11)

Ou seja, é necessário oferecer mecanismos de acesso às pessoas independente de suas características/limitações, sempre respeitando suas escolhas, garantido que não ocorra uma supressão de vontades, para que assim não troquemos uma forma de exclusão por outra, considerando a possibilidade de retirarmos as pessoas de um grupo compreendido como vulnerável e a coloquemos no grupo dos incapazes de tomarem decisões ${ }^{10}$, de serem cidadãos.

Deste modo, ao entrelaçarmos a Educação Matemática com a Educação Inclusiva, temos a possibilidade de discutir propostas para que o as práticas e metodologias utilizadas por professores, educadores e pesquisadores garantam essa qualidade no ensino. Pois, consoante a Mendes (2009, p. 24, grifo nosso), "[...] a Educação Matemática tem se preocupado com as contribuições possíveis de serem dadas pela Matemática na formação integral do cidadão".

Neste sentido,

\footnotetext{
10 É importante salientar que dependendo da característica do sujeito, talvez essa supressão de escolha seja necessária.
} 
Embora o objeto de estudo da EM [Educação Matemática] se encontre em processo de construção, poderíamos, de modo geral, dizer que ele envolve as múltiplas relações e determinações entre ensino, aprendizagem e conhecimento matemático em um contexto sociocultural específico. Isso não significa que uma determinada investigação não possa priorizar o estudo de um desses elementos, ou de uma dessas relações. Mas, mesmo que isso aconteça, outros elementos jamais podem ser totalmente ignorados. Por exemplo, se o foco de estudo for o ensino, o pesquisador não pode ignorar que se trata do ensino da matemática, o qual só faz sentido se considerar a existência de aprendizes enquanto sujeitos sociais. (FIORENTINI; LORENZATO, 2007, p. 9-10, grifo nosso)

Nessa perspectiva, ao visualizarmos essa proposição da Educação Matemática com a ótica da inclusão, temos que "[...] a sociedade assume um novo padrão referencial, exigindo que os sujeitos sociais, para que sejam considerados iguais, apresentem-se imbuídos de uma racionalidade especifica" (BONETI, 2003, apud BUCCIO; BUCCIO, 2008, p. 26, grifo nosso).

Entretanto, chamamos a atenção para o que devemos compreender por "igual e/ou igualdade", presente em diversos discursos sobre inclusão e educação.

Igualdade, um dos princípios fundamentais da Educação Inclusiva, não é, de forma alguma, tornar igual, Incluir não é nivelar nem uniformizar o discurso e a prática, mas exatamente o contrário: as diferenças, em vez de inibidas, são valorizadas. Portanto o "aluno-padrão" não existe: cada integrante deste cenário deve ser valorizado como é, e todo o processo de ensino-aprendizagem deve levar em conta estas diferenças (SANTOS; PAULINO, 2008, p.12, grifo do autor).

Sendo assim, vislumbramos uma educação para todos a partir da perspectiva da Educação Inclusiva e das premissas da Educação Matemática, de forma que compreendemos a necessidade de respeitar e garantir o (re)conhecimento do aluno como sujeito individual participante da construção do próprio saber e aprendizado.

\section{Considerações finais}

Entrelaçar caminhos, percepções e valores em relação ao ensino da matemática para alunos com alguma dificuldade no processo de ensino e aprendizagem, versa por diferentes contextos e realidades que precisam ser compreendidas e respeitadas pelos participantes deste processo, no qual os estudantes, também, são construtores do seu próprio saber e conhecimento.

Essa maneira de visualizar o ensino corrobora com a importância deste estudo, pois ao refletir acerca da importância do re/conhecer a individualidade do sujeito e necessidade de encontrar uma forma de comunicação que permita uma interação para o processo socioeducacional, nos permite, mesmo que de forma singela, contribuir para que a inclusão deixe de ser uma utopia e passe a se tornar uma realidade em processo de latência, como percebemos no caso "Ana" que pode se sentir, ao menos naquele momento, um membro ativo daquele grupo de alunos, e para isso, foi apenas preciso que as pessoas ali presentes se permitissem interagir com ela a partir do reconhecimento de uma parcela significativa de suas peculiaridades como estudante. 
Deste modo, entendemos que a Educação Matemática, para que tenha um caráter realmente inclusivo, não está apenas na metodologia adotada pelo professor, e sim a disposição de profissional em conhecer cada aluno como único, e a partir daí oferecer sua metodologia, reconhecendo e respeitando as diferenças de cada estudante, seja ele com ou sem deficiência.

\section{Referências}

ALMEIDA, W.G. A educação de surdocegos: novos olhares sobre a diferença. In: ALMEIDA, W.G. (org.). Educação de surdos: formação, estratégias e prática docente. Ilhéus: Editus, 2015. ALRO, H.; SKOVSMOSE, O. Diálogo e aprendizagem em educação matemática. Belo Horizonte: Autêntica, 2006.

BRASIL. Decreto n 5.626, de 22 de dezembro de 2005. Regulamenta a Lei no 10.436, de 24 de abril de 2002, que dispõe sobre a Língua Brasileira de Sinais - Libras, e o art. 18 da Lei no 10.098, de 19 de dezembro de 2000.

BRASIL. Lei n 9.394, de 20 de dezembro de 1996. Estabelece as diretrizes e bases da educação nacional.

BRASIL. Ministério da Educação. Secretaria de Educação Especial. Política Nacional de Educação Especial na Perspectiva da Educação Inclusiva. Brasília: Ministério da Educação, 2008.

BUCCIO, M. I.; BUCCIO, P. A. Educação Especial: uma história em construção. 2. ed. Curitiba: Ibpex, 2008.

CAPOVILLA, F. C.; RAPHAEL, W. D.; MAURICIO, A. C. L. Novo Deit-Libras: Dicionário Enciclopédia Ilustrado Trilíngue da Língua de Sinais Brasileira (Libras) baseado em Linguística e Neurociências Cognitivas. Volume 2: Sinais de I a Z. 2. ed. rev. e ampl. São Paulo: Edusp, 2012.

D'AMBROSIO, U. Da realidade à ação: reflexões sobre educação e matemática. 5. ed. São Paulo: Summus, 1986.

D'AMBROSIO, U. Educação Matemática: da teoria à prática. 16. ed. Campinas: Editora Papirus, 2008.

DANYLUK, O. Alfabetização matemática: as primeiras manifestações da escrita infantil. Porto Alegre: Sulina, 2002.

FERREIRA, A. B. Novo dicionário eletrônico Aurélio versão 5.11a. Curitiba: Positivo, 2004. 1 CDROM..

FIORIENTINI, D.; LORENZATO, S. Investigação em educação matemática: percursos teóricos e metodológicos. 2. ed. rev. São Paulo: Autores associados, 2007.

INSTITUTO BENJAMIN CONSTANT - IBC. Conceituando a surdocegueira. 2018. Disponível em: http://www.ibc.gov.br/paas/308-conceituando-a-surdocegueira. Acesso em: 10 mar. 2019. 
LIMA, M. S. Surdez, bilingüismo e inclusão: entre o dito, o pretendido e o feito. 2004. 261f. Tese (Doutorado em Lingüística Aplicada) - Universidade Estadual de Campinas, Campinas, 2004.

MENDES, I. A. Matemática e investigação em sala de aula: tecendo redes cognitivas na aprendizagem. ed. rev. e aum. São Paulo: Editora Livraria da Física, 2009.

PINTO, C. R. Foucault e as constituições brasileiras: quando a lepra e a peste encontram os nossos excluídos. Educação e Realidade, Porto Alegre, v. 24, n. 2, p. 15-32, jul./dez. 2000.

PONTE, J. P. et al. Didáctica da Matemática. Lisboa: Ministério da Educação, Departamento do Ensino Secundário, 1997.

RODRIGUES, D. (org.). Inclusão e educação: doze olhares sobre educação inclusiva. São Paulo: Summus, 2006.

SANTOS, M. P.; PAULINO, M. M. Inclusão em Educação: uma visão geral. In: SANTOS, M. P.; PAULINO, M. M. (org.). Inclusão em Educação: culturas, políticas e práticas. 2. ed. 3. reimpr. São Paulo: Cortez, 2008.

SKLIAR, C. A inclusão que é "nossa" e a diferença que é do "outro". In: RODRIGUES, D. (org.). Inclusão e educação: doze olhares sobre educação inclusiva. São Paulo: Summus, 2006.

SMITH, M.; RYNDAK, D. Estratégias práticas para comunicação com todos os alunos. In: STAINBACK, S. e STAINBACK, W. (org.). Inclusão: um guia para educadores. Porto Alegre: Artmed, 1999..

SOARES, J. B. Dicionário de Matemática. 5. ed. São Paulo: Hemus, 2005. 